\title{
The Cost Monitoring of the Construction Machinery with Using the Stochastic Progress-Based S-curves
}

\author{
Marek Krajňák, Renáta Bašková \\ Technical University of Košice, Slovakia \\ Civil Engineering Faculty, Institute of Civil Engineering Technology and Management \\ e-mail: marek.krajnak@tuke.sk, renata.baskova@tuke.sk
}

\begin{abstract}
Contribution presents methodology for evaluating at-completion project performance status. Accurate cost and schedule project forecasts are difficult to generate when considering the impact of such events as unforeseen cost changes, material delays, scope deviation, changes to the project execution plan and poor subcontractor performance. In reality, the original estimate may be considered the first project forecast and at the point of project completion, the latest updated estimate (last forecast) and the actual amount of what is being expended should be the same. Final project performance is determined by comparing the planned budget and project duration, with the expected forecasted final budget and elapsed time. The stochastic S-curve methodology permits objective evaluation of project performance without the limitations inherent in a deterministic approach. This paper used the stochastic $\mathrm{S}$ curve to monitor the cost and time consumption in operation of the construction machines. The contribution presents a partial outcome from the dissertation thesis called the Interactive tools for resource optimization in construction.
\end{abstract}

Key words: stochastic approach, construction machines performance, S-curves, forecast at-completion, evaluating at-completion, updated estimate, cost and time consumption

\section{Introduction}

The continuous evaluation of the planned and real cost is one from the essential assumptions for successful managing of the construction company [1], [2]. This conception creates a system of the reverse signalization, which in the real time continuously provides all necessary information about the cost consumption of the construction activities [3]. The effective utilization of the time fund in the context of the consumed cost is influenced by the many factors. There are a several researches, which define individual factors, which cause the deviations from the planned cost and planned duration of the construction projects. Zou et al. [4] pointed out at the fact that influence of the given factor has not be similar. Whereby is proved that between cost and time exists a big correlation dependence with influence rising of the given factors. Barraza et al. [5] divided the factors as follows: 
- unforeseeable circumstances;

- changes in the scope of the construction works;

- inflation of the construction works;

- the late delivery of the construction materials;

- weather conditions.

\section{Background of the integrated project performance forecasting}

Estimating both final cost and duration values can be performed using two different approaches: deterministic and probabilistic. The deterministic approach estimates final cost and project duration considering for the project activities the most likely cost and duration values, respectively. The probabilistic approach estimates the planned cost and duration values based on the variability of cost and duration inherent in each of the project activities. In spite of the improved representation of the variable behavior of projects that allows the probabilistic approach [6].

Issue of the project performance forecasting is often connected with methodology of Earned Value System (EVS). EVS is a project management technique for measuring project performance and progress. It has the ability to combine measurements of the project management triangle:

- scope;

- schedule;

- costs.

In a single integrated system, EVS is able to provide accurate forecasts of project performance problems, which is an important contribution for project management. Early EVS research showed that the areas of planning and control are significantly impacted by its use; and similarly, using the methodology improves both scope definition as well as the analysis of overall project performance. More recent research studies have shown that the principles of EVS are positive predictors of project success [7]. Popularity of EVS has grown in recent years beyond government contracting, in which sector its importance continues to rise [8].

\subsection{The cost monitoring with using the Progress-Based S-curves}

The construction projects are characterized by the inability of determination of the required duration and budget for the construction activities. This fact results from typical characters of the civil engineering, i.e. seasonality of the construction woks, a long execution cycle of the construction project etc. The estimates of the cost and time evaluation of the construction activities results from the data obtained from the past construction projects. The duration of the construction activity is determined by the concrete duration in the case of the deterministic approach. The stochastic methods reflect from the assumption that unique of the construction project does not allow to determine the duration of the individual activities directly with the sufficient precision.

The fundamental of the approach is an expression of the activity duration (resource consumption) by the form of random variable, which is defined by the probability distribution [9], [10]. Advantage of this approach is possibility to create scenarios, which can simulate the 
different situations. In this context the different scenarios (most probably, pessimistic, optimistic etc.) were applied.

Graphic description forms of the progress of the consumed time and consumed cost are different. S-curves are used mainly in abroad for this purpose. S-curve is a non-decreasing function, which express the cost and time status within the progress of construction project. These functions are known as Progress-based S-curves (PB S-curves) also. The vertical axis presents time and cost, horizontal axis presents progress of the construction (expressed in \%) (see Figure 1). The shape of the time or cost functions is influenced from the assumption, whether the consumption of the time and cost is uniform or different at the progress of the construction, in this case the function has a shape of inverted "S". In the opposite case function has a linear shape. Figure 1 shows PB S-curves for assumed cost and time (continuous curves) in the context of the consumed cost ant consumed time (dashed curves) in the progress point $\mathrm{w}_{\mathrm{i}}$. In the given progress point the deviation in the cost - Cost variation (CV) and a deviation in the time - Time variation (TV) was determined. The stated deviations help us to accept a decision making. Disadvantage of the PB S-curves is fact that the development of the curves in the future is not possible to assume. For example it is not possible to determine assumption, whether cost will return into the budget in the next progress of the construction.

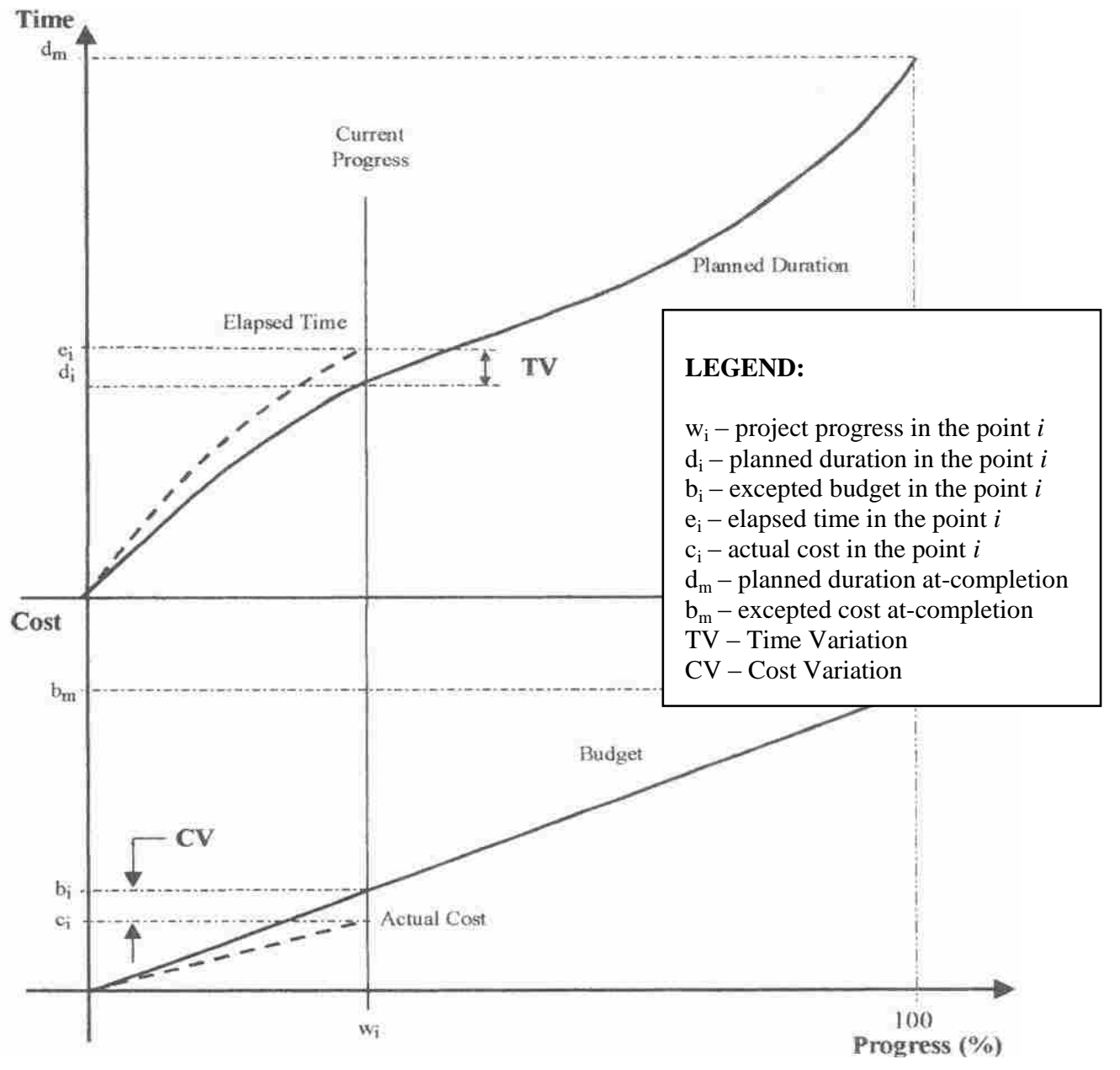

Figure 1: Progress-Based S-curves (Source: [3]) 
The deviations in the cost and duration of the construction activities are a usual event, which is impossible to eliminate completely. Mesároš [11] states a maximal deviation from the actual cost at the level $\pm 5 \%$, provided that we consider:

- detailed calculation of the own cost,

- inflation,

- and entire construction project documentation.

This state takes into account by using stochastic PB S-curves (PB SS-curves), which consider with dispersion of the values around the mean of random variable. The advantage of the PB SS-curves is possibility to determine TV and CV deviations in the given progress point $\mathrm{w}_{\mathrm{i}}$. From this point it can be draw a new trend of the PB SS-curves, which have assigned a probability distribution (see Figure 2). Consequently it is possible to compare the Estimate At-Completion (EAC) with the expected Budget At-Completion (BAC) (in the view of cost aspect), respectively to compare the elapsed Time At-Completion (TAC) with the expected Duration At-Completion (DAC) (in the view of time aspect). An assumption, whether reach the values from the initial BAC or DAC distribution in the progress point $100 \%$ (Atcompletion) is expressed. In addition mutual interactions between time and cost development are tracked. The most important is to adopt the most probability scenario development for decision making. Practically in the progress point $\mathrm{w}_{\mathrm{i}}$ is created a new assumption, which takes into account the current state of the present development.

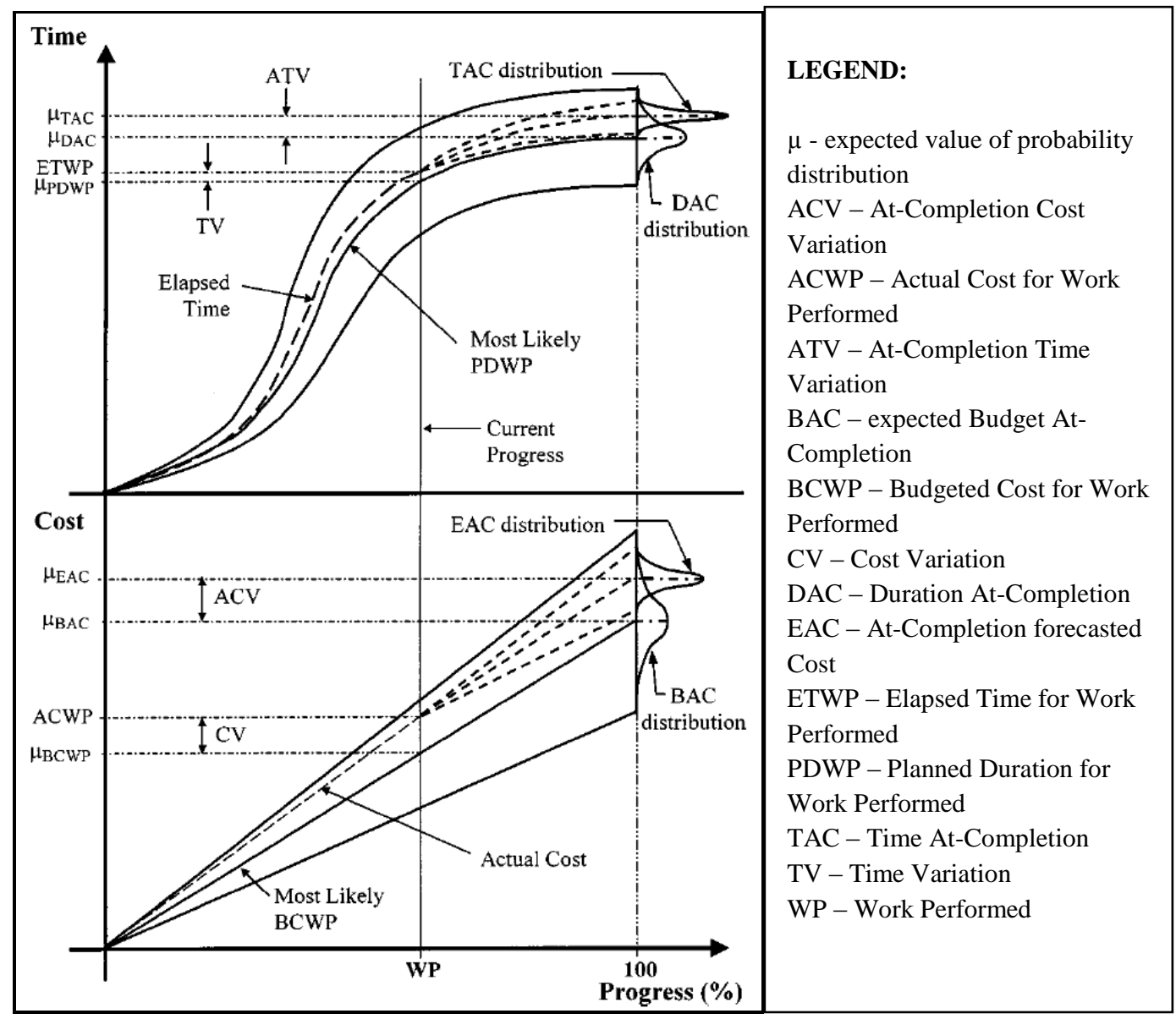

Figure 2: Stochastic Progress-Based S-curves (Source: [12]) 


\section{Objective}

The research described in this paper has the objective of applying the methodology for using probabilistic PS-curves to determine at-completion project performance of the construction machines. An application of this methodology on the fictional case study is presented.

\section{Methodology and material}

The cost monitoring at the construction machines operation allows continuous comparison the planned cost with the actual cost, fast improvement of the deviations from the determined assumption and searching bottlenecks. The authors have pointed out to the fact that detailed cost planning is possible to obtain the economic advantage for construction companies [13], [14]. Assakkaf [15] stated that cost for construction machinery is the second most important factor (just after the construction resources). This fact influences significantly the result of the economic condition of construction company and emphasizes the demand of the detailed cost assumption for construction machinery [16], [17]. The displaying of the consumed cost at the construction machinery operation by using S-curves is suitable mainly for conceptual managing of the construction machine, but for operational managing level also.

\subsection{Defining the scope of the fictional case study}

The concrete case was created for proving of the PB SS-curves potential. The case study simulates the employment of the construction machine in the real conditions. The stated case has determined conditions as follows: the planned cost of the construction machine reflect to month fund 185 hours. The inflation grows is considered (fuels, oils, wages of operators, repairs...). The designed month fund of hours presents optimal working fund, and thus the construction machine works at minimal rate of hour cost. Duration of the mechanized construction works is assumed to 8 months, it was considered with constant work volume in particular months. The financial sanction per diem of delay presents $200 € /$ day $(0.3 \%$ from the planned cost $71632 €$ ), as well as the financial incentive in the case of the earlier completion of construction works (200 €/day). The consumption of the cost and time is constant within the construction progress that means the PB SS-curves have a linear shape. TV and CV deviations at-completion (in the progress point $\mathrm{w}=100 \%$ ) is determined by the probability distribution. The assumed cost and time development (Figure 3 - blue line) is compared in the context of the actual state in the progress point $w_{50}$ (Figure 3 - red curve). The red curve presents the changes in the employment of the construction machine:

- movement of the start date,

- interruption of the construction works (e.g. due to bad weather conditions),

- decreasing of performance of the construction machine.

The real development of the cost PB SS-curve and PB SS-time curve differs from the planned status. TV deviation gradually starts to expand, but to $\mathrm{CV}$ deviation is minimal (in the progress point $15.5 \% ; 25 \% ; 37.5 \%$ ). A big expanding of $\mathrm{CV}$ deviations starts in the time when expected duration of the construction works is elapsed (in the progress point $75 \%$ ). The expanding of the $\mathrm{CV}$ deviation has an exponential shape (Figure 3 - red dashed curve). The 
final result is 3 months delay and addition cost $19134 €$. This outcome is completely outside of the initial scope of the random variable BAC.
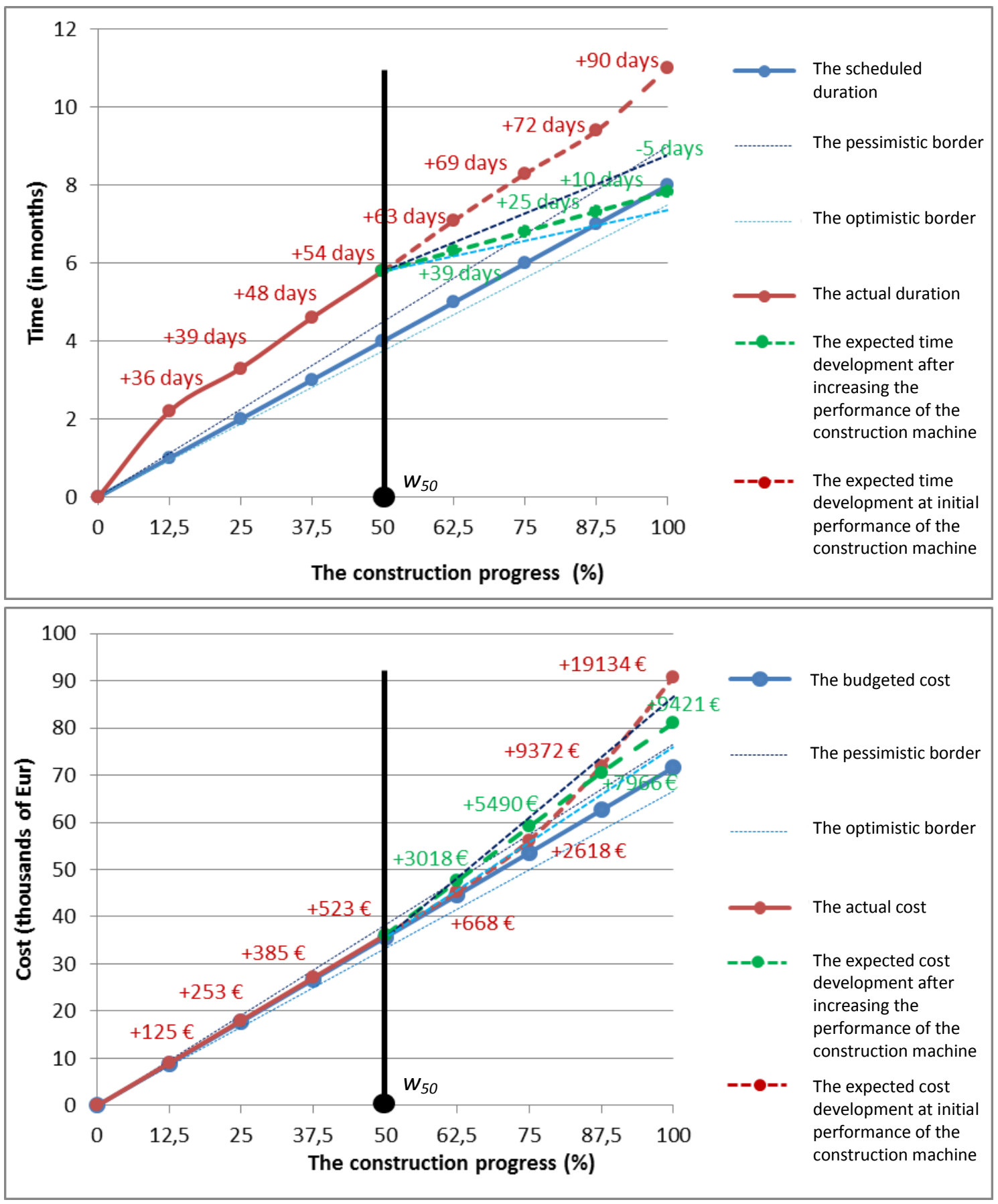

Figure 3: Stochastic PB S-curves of construction machine operation (Source: Authors)

To simulate a possibility of reversion of the development was increased the performance of the construction machine from the progress point $50 \%$. The aim was defined as follows:

- to observe a contract deadline; 
- to stop a gradually increasing of the cost deviation, resp. to eliminate the addition cost at-completion.

The performance of the construction machine was increased to 360 working hours, in order to meet a determined aim. This solution bought addition cost for overtime work, work over weekend etc. In addition the construction machine does not work at minimal unit cost now.

\section{Results and conclusion}

The result is expressed by dashed green curves. The TV deviation gradually starts to decrease, on the contrary the CV starts to increase after measures were adopted (from the progress point 50\%). Finally, the construction works were finished 5 days earlier. The addition cost we cannot eliminate completely, but on the other hand there are no financial sanctions. We can conclude that $\mathrm{CV}$ deviation was not stopped, but the rate of the increase was slowed down. The final cost deviation presents $9421 €$.

There is an assumption that construction projects will be contracted in most of construction projects according the yellow book of FIDIC (Fédération Internationale Des IngénieursConseils) in the future. These contract conditions (in contrast to red book of FIDIC) create a space for contractors, so they have possibilities to adapt the construction project to their technological and capacitance options. On the other hand contractor has to be responsible that will observe a determined budget and date of contract completion. It is clear in this case that accent to prediction and managing of economic risks will be even stronger till now. In addition the share of the mechanized work in the construction projects is so significant that planning and backward valuation of the employment of the construction machines is necessary assumption for successful managing of the construction machines

\section{Acknowledgements}

The article presents a partial research result of project VEGA - 1/0677/14 "Research of construction efficiency improvement through MMC technologies".

\section{References}

[1] Tažiková, A. and Kozlovská, M. (2013). Approach to estimated construction time for project management. In: ITCRES 2013: Innovative trends in construction and real estate sector. Bratislava: STU, p. 1-11. - ISBN 978-80-227-3932-0.

[2] Kozlovská, Mária (2013). Key factors of the managing of the construction projects (In Slovak: Klúčové riziká riadenia stavebných projektov). In: Oceňovanie a riadenie stavebných projektov. Košice : TU, p. 62-69. - ISBN 978-80-553-1417-4.

[3] Mesároš, F. and Mesároš, P. (2009). Controlling nákladov na stavebné procesy. Košice: VÚSI. $220 \mathrm{p}$.

[4] Zou, P.X.W., Zhang, G., Wang, J.(2007). Understanding the key risks in construction projects in China. International Journal of Project Management (25), p. 601-614. 
[5] Barraza, Gabriel A., Back, W. Edward, Mata, Fernando (2004). Probalistic forecasting of project performance using stochastic S curves. Journal of Construction Engineering and Management. 130 (1), p. 25-32.

[6] Crandall, K. C., and Woolery, J. C. (1982). Schedule development under stochastic scheduling. J. Constr. Div., Am. Soc. Civ. Eng., 108(2), 321-329.

[7] Marshall, Robert. The Contribution of Earned Value Management to Project Success of Contracted Efforts. Journal of Contract Management, 2007, pp. 21-331.

[8] A Guide to the Project Management Body of Knowledge. Newtown Square, PA: Project Management Institute. 2013. pp. 217-219.

[9] Cheng, T., Venugopal, M., Teizer, J., Vela, P., A.(2011). Performance evaluation of ultra wideband technology for construction resource location tracking in harsh environments. Automation in Construction. 20 (8), 1173-1184. DOI: 10.1016/j.autcon.2011.05.001.

[10] Han, S., Lee, S., Hong, T., Chang, H. (2006). Simulation analysis of productivity variation by global positioning system (GPS) implementation in earthmoving operations. Canadian Journal of Civil Engineering . 33 (2), 1105-1114.

[11] Mesaroš, F. (2009). Oceňovanie stavebných prác z hl'adiska času a presnosti. In: Realizácia a ekonomika stavieb, Košice : Dom techniky, p.150- 156 - ISBN 978-80-232-0301-1.

[12] Barraza, Gabriel A., Back, W. Edward, Mata, Fernando (2006). Probalistic monitoring of project performance using SS curves. In: Journal of Construction Engineering and Management. 126 (2) p. 142-148.

[13] Radziszewska-Zielina, E., Sobotka, A., Plebankiewicz, E., Zima, K (2013). Preliminary identification and evaluation of parameters affecting the capacity of the operator-earthmoving machine system, Budownictwo i architektura, 12 (2), pp. 53-60.

[14] Struková, Z., Ištvánik, M. (2011) Tools for mobile crane selecting and locating, International Review of Applied Sciences and Engineering, 2, pp. 69-74.

[15] Assakkaf, I. ENCE 420 - Construction Equipment and Methods [online]. http://www.assakkaf.comCoursesENCE420Lectureschapter3c.pdf

[16] Gašparík, J. et al. (2013). Multi-criteria optimizing method of earthwork machine group selection implemented into soil processes, ISARC 2013 - 30th International Symposium on Automation and Robotics in Construction and Mining, Montreal, , pp. 448-458.

[17] Milajić, A. et al. (2011). Genetic algorithms for assigning tasks to construction machine operators, Gradevinar, 63(8), pp. 749-755. 